\title{
Biotransformation, genotoxic, and histopathological effects of environmental contaminants in European eel (Anguilla anguilla L.)
}

\author{
Mário Pacheco* and Maria Ana Santos \\ Animal Physiology/Ecotoxicology Sector, Biology Department, University of Aveiro, Aveiro 3810-193, Portugal \\ Received 7 May 2000; received in revised form 30 March 2001; accepted 30 April 2001
}

\begin{abstract}
A prolonged toxicity study was carried out in young European eel (Anguilla anguilla L.) to evaluate the effects of environmental contaminants, namely, two individual standard compounds, benzo[ $a]$ pyrene $(\mathrm{BaP})$ and dehydroabietic acid (DHAA), and a complex mixture, bleached kraft pulp mill effluent (BKPME). Fish were exposed to BaP $(0.22,0.45$, and $0.9 \mu \mathrm{M})$ and BKPME $(3.12 \%$, $6.25 \%$, and $12.5 \%(\mathrm{v} / \mathrm{v}))$ for 3,7 , and 30 days and to DHAA $(0.07,0.15$, and $0.30 \mu \mathrm{M})$ for $3,7,30,90$, and 180 days. The biomarkers include biotransformation and genotoxicity indicators, such as total ethoxyresorufin $O$-deethylase (EROD) activity and frequency of erythrocytic nuclear abnormalities (ENAs), respectively. Hematological dynamics was assessed as frequency of immature erythrocytes (IEs). Histopathological examinations were carried out for the highest concentrations and for 30 days and longer exposures. Total EROD increases significantly only after 180 days of DHAA exposure. However, significant ENA induction was generally observed during exposure to all contaminants tested. Nevertheless, some of the ENA results suggest an altered genotoxic response, which may arise either from short-term exposures to the highest contaminant levels or long-term exposures to the lowest contaminant levels. IE frequency decreased significantly after 30 days of exposure to $0.45 \mu \mathrm{M} \mathrm{BaP}$ and 180 days of exposure to the entire DHAA concentration range. Increased density of pigmented macrophage aggregates in 30-day BaP- and BKPME-exposed fish as well as in 90- and 180-day DHAA-exposed fish confirmed histopathological liver alterations. Bile accumulation in hepatocytes after BaP treatment, cytoplasmic vacuolization and cell atrophy following DHAA exposure, as well as liver loss of parenchymal cells in BKPME-exposed fish, were also detected. Dispersed necrosis and focal inflammation were observed in the livers of all treated groups. Fish exposed to DHAA and BKPME showed skin and gill disruption as well as kidney Malpighian corpuscle alterations. All 30-day-treated groups revealed intense spleen hemosiderosis, indicating increased erythrophagia. This splenic effect may be strongly correlated with the observed disappearance of ENAs. Neoplastic lesions were not found. A multibiomarker strategy, which includes EROD, ENA, and IE assays as well as histopathological studies, contributed to a better understanding of the global toxic process.
\end{abstract}

(C) 2002 Elsevier Science (USA). All rights reserved.

Keywords: Anguilla; Ethoxyresorufin $O$-deethylase; Genotoxicity; Histopathology; Pulp mill effluent; Resin acids; Benzo[a]pyrene

\section{Introduction}

Fish respond to environmental pollutants by altering/ adapting their metabolic functions. Among the variety of biomarkers adopted in ecotoxicological investigations, there is notable interest in parameters related to enzymatic xenobiotic detoxification and activation (biotransformation). In this context, cytochrome P450dependent monooxygenase induction, measured as ethoxyresorufin $O$-deethylase (EROD) activity, has been

\footnotetext{
*Corresponding author. Fax: 351-234-426-408.

E-mail address: mpacheco@bio.ua.pt (M. Pacheco).
}

widely used as a sensitive indicator of exposure to environmental contaminants (Addison et al., 1994; Martel et al., 1994; Pacheco and Santos, 1999). The activation of certain xenobiotics results in the production of potentially damaging oxyradicals, which react with many biological molecules including DNA (Di Guilio et al., 1989). Thus, DNA integrity can be affected. Considering the risks associated with DNA damage, the implementation of genotoxicity biomarkers such as DNA adducts (Harvey et al., 1997), DNA strand breaks (Everaarts, 1995), micronuclei (Jaylet et al., 1986) and erythrocytic nuclear abnormalities (ENAs) (Pacheco and Santos, 1996, 1999) is of particular importance. 
Disturbance of living processes at the molecular and subcellular levels of biological organization by xenobiotics frequently leads to cell injury resulting in degenerative and neoplastic diseases in target organs. Therefore, histopathological biomarkers have been proven to be useful complementary indicators of toxicity in fish organs (Schwaiger et al., 1996; Teh et al., 1997).

The information provided by each biomarker individually is of limited relevance, as there is a considerable likelihood of misinterpretation. According to Moore and Simpson (1992), it must be emphasized that biomarkers are best used as selected batteries of tests rather than individually. Thus, interlinking of the results obtained at different biological levels, such as molecular (biotransformation metabolism), subcellular (genotoxicity expression), and cellular/tissue (histopathological effects) levels, may lead to a substantial improvement in the knowledge of integrated fish toxic response.

The environmental contaminants tested in the present study include two individual chemicals - benzo $[a]$ pyrene $(\mathrm{BaP})$, a polycyclic aromatic hydrocarbon $(\mathrm{PAH})$, and dehydroabietic acid (DHAA), a resin acid - as well as a complex mixture, bleached kraft pulp mill effluent (BKPME). BaP, a PAH commonly found in contaminated environments, is recognized as a biotransformation inducer (Wolkers et al., 1996; Pacheco and Santos, 1998) with strong genotoxic and carcinogenic potential in fish (Hendricks et al., 1985; Hawkins et al., 1990; Pacheco and Santos, 1997). Effluents from the wood processing industry are one of the most significant sources of aquatic pollution worldwide. Resin acids are important BKPME components and DHAA in particular is considered a major poison to fish. Previous studies have indicated that either DHAA or BKPME as a whole induce alterations at different biological levels, namely, biotransformation activation (Martel et al., 1994; Pacheco and Santos, 1999) and genotoxicity (Pacheco and Santos, 1997, 1999).

The study described here on the toxicity of environmental pollutants in young specimens of Anguilla anguilla L. after prolonged exposure had two main objectives: (i) the assessment of BaP, DHAA, and BKPME effects as total EROD activity, alterations in immature erythrocyte frequency and ENA induction, as well as their histopathological effects on different fish target organs (skin, gills, kidney, spleen and liver); (ii) an attempt to relate the preceeding biomarkers to improve our understanding of the fish toxic response as an integrated process.

\section{Materials and methods}

\subsection{Test contaminants}

BaP was obtained from Sigma Chemical Company (USA). DHAA was obtained from Helix Biotech
Corporation (Canada). The neutralized and secondarily treated BKPME was collected from a pulp and paper mill sewage outlet (Portucel - Cacia, Aveiro, Portugal). This mill produces bleached kraft pulp and paper, using Eucalyptus globulus and Pinus pinaster $(75 \%$ and $25 \%$, respectively) as wood supply.

\subsection{Fish}

European eel (A. anguilla) young specimens, with an average weight of $0.2 \mathrm{~g}$ (glass eels), were caught in October at the Mondego River mouth, Figueira da Foz. They were transported to the laboratory and allowed to acclimate ( 2 weeks) to controlled conditions, i.e., in recirculating, filtered, well-aerated, and dechlorinated tap water, at $20^{\circ} \mathrm{C}$, under a natural photoperiod. Fish were fed three times a week, either in the recovery period or during the experiments.

\subsection{Experimental design}

Fish exposure took place in 15-L aquaria, containing 70 fish each, under the previously described conditions. A 2-cm layer of washed sand was placed on the aquarium bottom. The initial/nominal exposure concentrations were $0.22,0.45$, and $0.9 \mu \mathrm{M}$ for $\mathrm{BaP}, 0.07$, 0.15 , and $0.3 \mu \mathrm{M}$ for DHAA and $3.12 \%, 6.25 \%$, and $12.5 \%(\mathrm{v} / \mathrm{v})$ for BKPME. The concentration ranges selected were based on our previous studies (Pacheco and Santos, 1997, 1999). Half of the test solution in each aquarium was renewed weekly. Fish sampling was carried out at 3, 7, 30, 90, and 180 days. However, considerable mortality was observed after 30 days exposure in $\mathrm{BaP}$ and $\mathrm{BKPME}$ experiments, preventing continuation of the experiment beyond that exposure length.

Fish were killed by decapitation. At each sampling point, five fish were collected and immediately frozen in liquid nitrogen for homogenization and microsomal isolation, and another five eels were collected for blood sampling. Additionally, histology was carried out at 30 days and longer exposures where three eels were collected from test groups at highest concentrations.

$\mathrm{BaP}$ and DHAA added to the experimental aquaria were previously dissolved in dimethyl sulfoxide (DMSO). The DMSO concentration in water $(0.033 \%$ ) has no detectable cytogenetic or toxic effect. The same DMSO level was maintained in the control aquarium. The BKPME control aquarium contained only clean water.

\subsection{EROD assay}

The whole eel's body was used for microsomal isolation and EROD activity measurement. Microsomes were obtained according to the methods of Lange et al. 
(1993) and Monod and Vindimian (1991) as adapted by Pacheco and Santos (1997). Total EROD activity was measured as described by Burke and Mayer (1974), and the results were expressed as $\mathrm{pmol} / \mathrm{min} / \mathrm{mg}$ of microsomal protein. Microsomal protein content is determined according to the Biuret method (Gornall et al., 1949).

\subsection{Mutagenicity testing}

Mutagenicity was tested using the ENA assay, according to the procedure adapted by Pacheco and Santos (1996). Each group's final result was presented as the mean value (\%) of the sums for all the individual lesions observed and scored in 1000 mature erythrocytes per fish blood smear.

\subsection{Immature erythrocytes (IE) frequency}

IEs were scored on each 1000-erythrocyte (mature and immature) sample per fish. Results are presented as a frequency (\%o) obtained using the expression

IE frequency $(\%)=\frac{\text { No. IEs }}{(\text { No. IEs }+ \text { No. MEs })} \times 1000$

$(\mathrm{ME}=$ mature erythrocytes $)$.

\subsection{Histopathology}

The whole fish body was fixed in Bouin's solution and routinely embedded in paraffin for light microscopy. The section thickness was $5 \mu \mathrm{m}$. Sections were stained with hematoxylin and eosin (HE). Histological criteria employed in lesion classification were derived from criteria previously established for fish by Hibiya (1982) and Myers et al. (1987).

\subsection{Statistical evaluation}

Means \pm standard errors (SE) were calculated for each experimental group. Data were analyzed for significance of differences between control and each exposed group according to the two-tailed Student's $t$-test (Bailey, 1959).

\section{Results}

\subsection{EROD response}

$\mathrm{BaP}$ and BKPME exposures did not induce any significant alteration in the total EROD activity (Figs. 1A and 3A). Regarding the DHAA experiment, exposures from 3 to 90 days also did not reveal any significant increase (Fig. 2A). However, after 180 days exposure a clear dose-response relation was observed, and a significant increase was noted for 0.15 and $0.30 \mu \mathrm{M}(P<0.05)$.

\subsection{ENA response}

The results of the $\mathrm{BaP}$ experiment displayed a significant ENA increase after 3 days exposure to $0.45 \mu \mathrm{M}(P<0.05)$, followed by an accentuated decline after 7 days exposure (Fig. 1B). At 30 days exposure, the highest $\mathrm{BaP}$ concentrations remained incapable of ENA elevation, whereas the lowest concentration $(0.22 \mu \mathrm{M})$ induced a significant ENA increase $(P<0.002)$. Furthermore, at this exposure length $0.9 \mu \mathrm{M}$ BaP presented an ENA value significantly lower than $0.22 \mu \mathrm{M}(P<0.05)$.

The analysis of genotoxic response to DHAA demonstrated that, after 3 days exposure, ENA frequency was significantly elevated by the highest concentration $(0.30 \mu \mathrm{M} ; P<0.01)$ (Fig. 2B), whereas 7 and 30 days exposure did not produce any statistical significant alteration, despite an evident general ENA increase. At 90 days exposure, the highest DHAA concentrations induced a significant ENA increase $(P<0.01$ for $0.15 \mu \mathrm{M}$ and $P<0.001$ for $0.30 \mu \mathrm{M})$. From 90 up to 180 days exposure, ENA frequency was notably increased by 0.15 and $0.30 \mu \mathrm{M}$ DHAA $(P<0.01$ and $P<0.05$, respectively).

The ENA results of the BKPME experiment (Fig. 3B) demonstrated a significant increase for 7 days exposure to the lowest concentration $(3.12 \%, P<0.01)$. Additionally, the highest BKPME concentration (12.5\%) exhibited the lowest ENA frequencies along the 30 days exposure. Furthermore, at 30 days exposure all BKPME concentrations displayed ENA levels below the control, being particularly significant for $3.12 \%$ and $12.5 \%$ $(P<0.05$ and $P<0.01$, respectively).

\subsection{Hematological dynamics (IE frequency)}

The IE frequency (Figs. 1C, 2C and 3C) was generally decreased by all tested contaminants after 30 days and longer exposures. However, this decrease was statistically significant only for 30 days exposure to $0.45 \mu \mathrm{M}$ $\mathrm{BaP}(P<0.05)$ and for 180 days exposure to all DHAA concentrations $(P<0.05, \quad P<0.002$, and $P<0.001$, respectively for $0.07,0.15$, and $0.30 \mu \mathrm{M}$ ).

\subsection{Histological examination}

Exposures to $0.9 \mu \mathrm{M}$ BaP, $0.3 \mu \mathrm{M}$ DHAA, and $12.5 \%$ BKPME revealed the following histological findings.

\subsubsection{Skin}

Thirty-day exposures to DHAA and BKPME caused evident skin disruption. Accentuated reduction of skin thickness and large portions of exfoliated epidermis were observed. Tissue destruction, frequently, reaches 

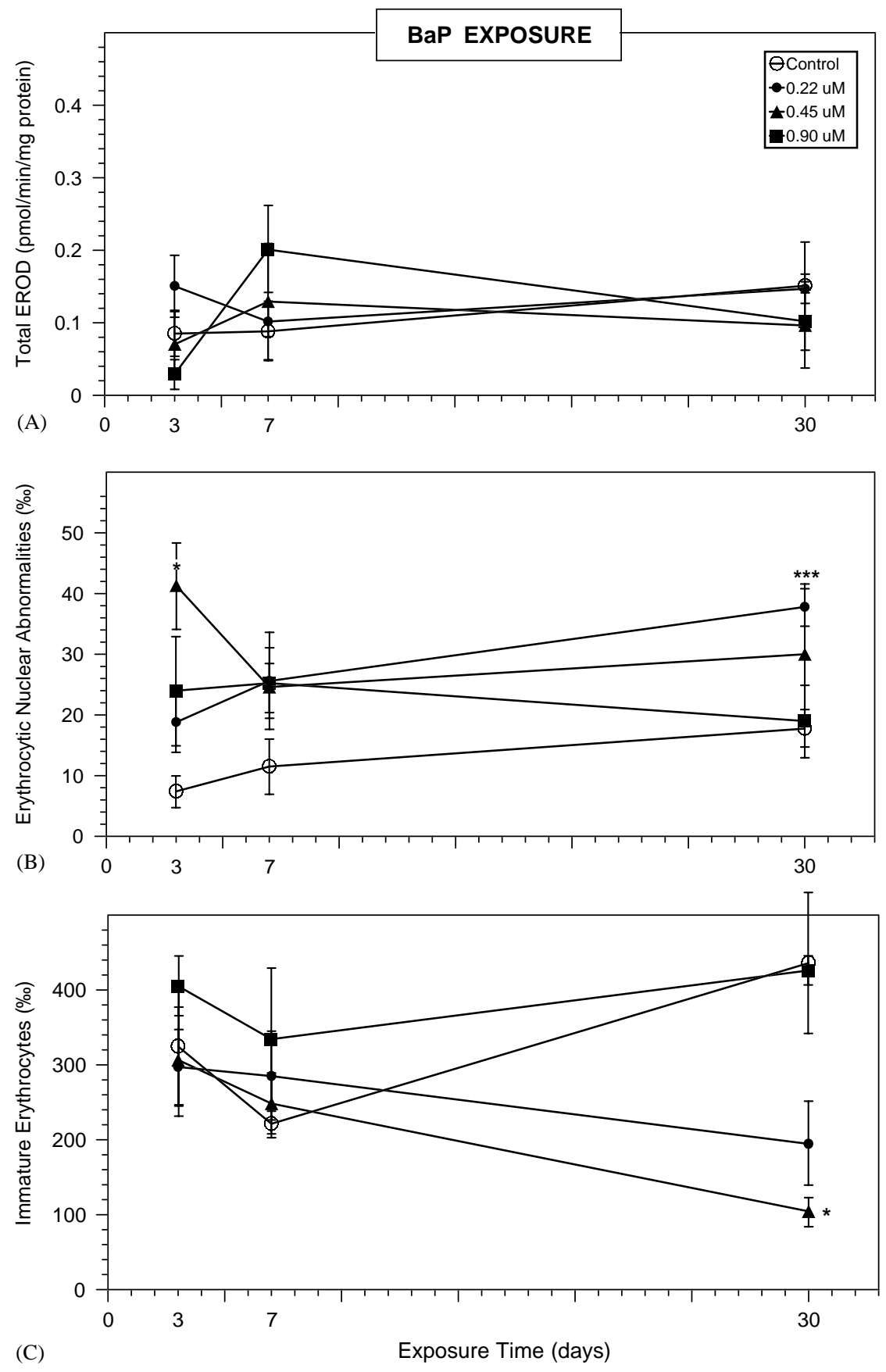

Fig. 1. Time- and dose-related $A$. anguilla response as total EROD activity (A), frequency of erythrocytic nuclear abnormalities (B), and frequency of IE (C) after exposure to benzo $[a]$ pyrene $(\mathrm{BaP}: 0.22,0.45$, and $0.90 \mu \mathrm{M})$ for 3 , 7, and 30 days. Values represent means and SE $(n=5 /$ treatment). Statistically significant differences between exposed fish and control fish: ${ }^{*} P<0.05 ;{ }^{* * *} P<0.002$.

the basal cell level (Figs. 4C and D). However, longer DHAA exposures (90 and 180 days) do not seem to cause severe skin damage. Epidermal hyperplasia associated with parasitosis (Ichthyophthirius multifiliis) was observed either in both control and BaP- and BKPME-treated fish (Fig. 4E). Therefore, regarding parasitosis and associated alterations, no distinct differences between exposed and control fish could be found. Nevertheless, DHAA-exposed fish did not display parasitic infection for any exposure time.

\subsubsection{Gills}

Fish exposed for 30 days to DHAA and BKPME exhibited edematous hypertrophy of covering epithelial cells in the secondary lamellae (Figs. 5D-F). This degenerative alteration was also detected after 90 and 

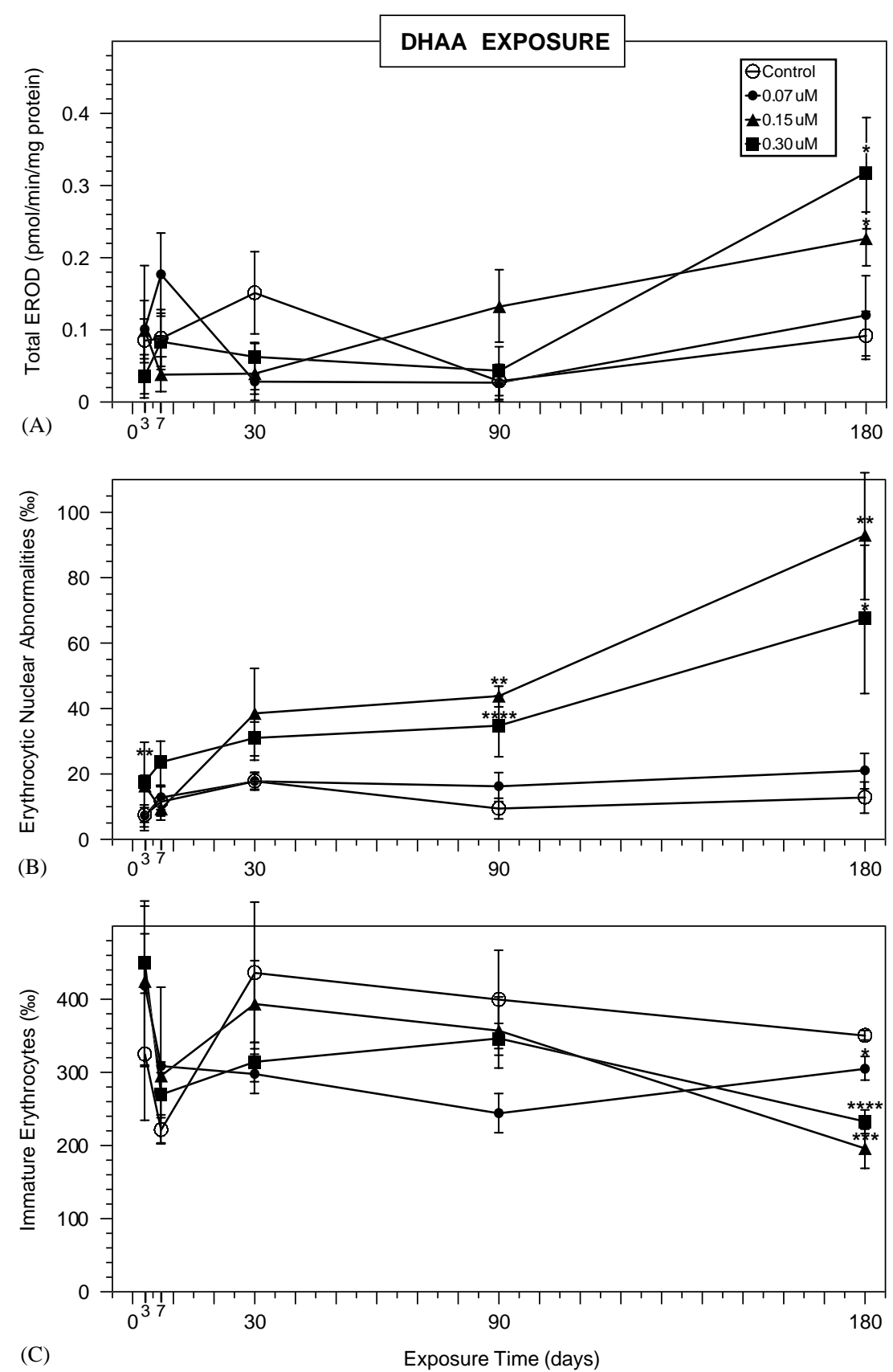

Fig. 2. Time- and dose-related $A$. anguilla response as total EROD activity (A), frequency of erythrocytic nuclear abnormalities (B), and frequency of IE (C) after exposure to dehydroabietic acid (DHAA: 0.07, 0.15, and $0.30 \mu \mathrm{M}$ ) for 3, 7, 30, 90, and 180 days. Values represent means and SE $\left(n=5 /\right.$ treatment). Statistically significant differences between exposed fish and control fish: ${ }^{*} P<0.05,{ }^{* *} P<0.01,{ }^{* * *} P<0.002,{ }^{* * * *} P<0.001$.

180 days of DHAA exposure, demonstrating a time dependence since it became more obvious at longer exposures. Proliferation of interlamellar cells and consequent fusion of adjacent secondary lamellae, forming club-shaped lamellae (Fig. 5C), were observed in 30-day BKPME exposed as well as 90- and 180-day DHAA-exposed fish. To a minor degree, the previous finding could also be observed in a few control fish, probably due to parasitic infection. The presence of ectoparasites (class Monogenea) was regularly detected between the secondary lamellae of both exposed and control eels.

\subsubsection{Kidney}

Considering the renal parenchyma and tubules, no pathological alterations were observed. Considering the renal corpuscle, dilation of blood capillaries on the glomeruli was detected in BKPME-treated fish (Figs. 6C 

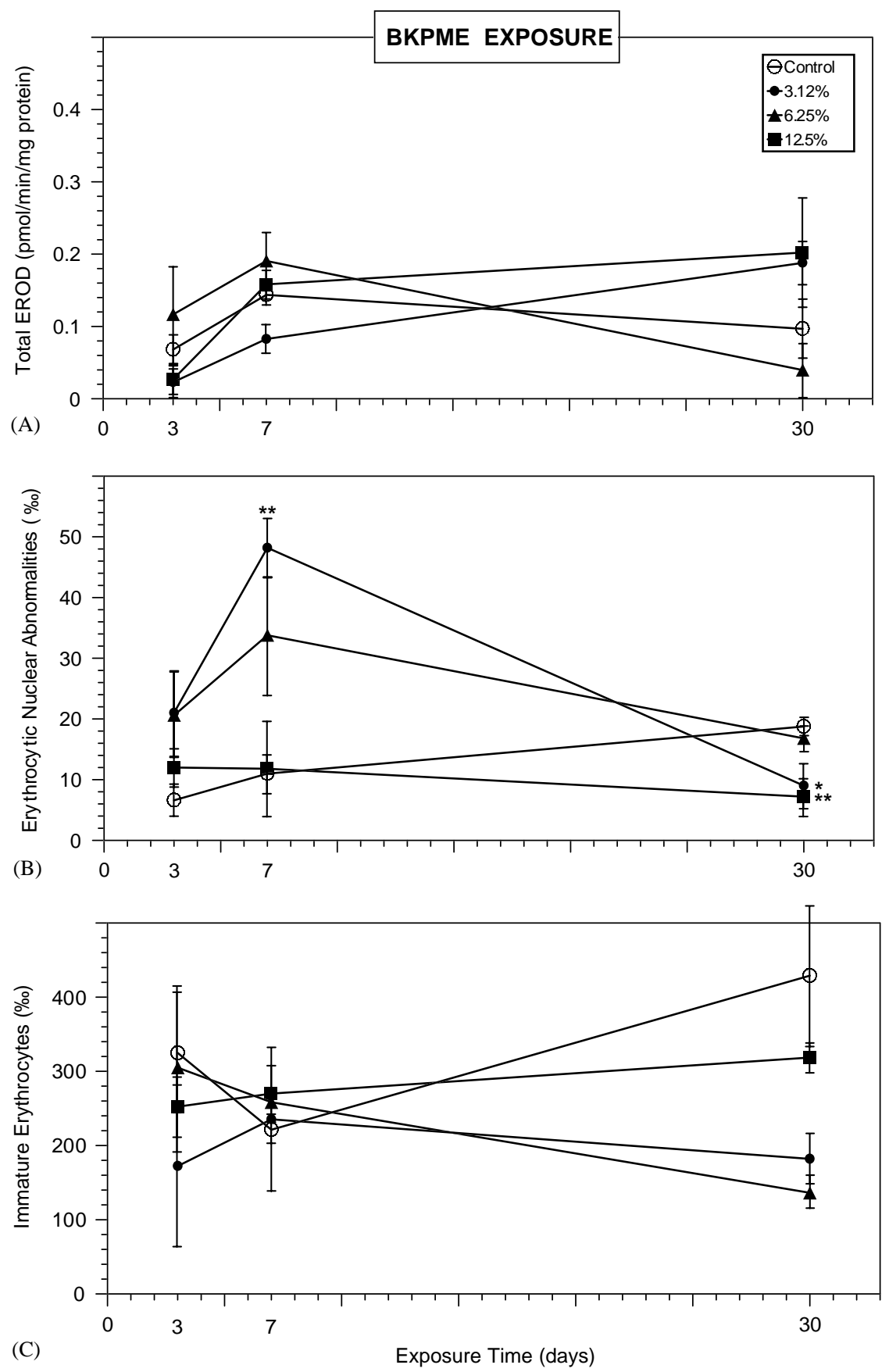

Fig. 3. Time- and dose-related $A$. anguilla response as total EROD activity (A), frequency of erythrocytic nuclear abnormalities (B), and frequency of IE (C) after exposure to bleached kraft pulp mill effluent (BKPME: 3.12\%, 6.25\%, and 12.5\%) for 3, 7, and 30 days. Values represent means and SE $(n=5 /$ treatment $)$. Statistically significant differences between exposed fish and control fish: ${ }^{*} P<0.05,{ }^{* *} P<0.01$.

and D). An increased Bowman's space and apparent glomerulus destruction were observed in fish exposed to DHAA for 180 days (Fig. 6B).

\subsubsection{Spleen}

After 30 days exposure, hemosiderosis regularly developed in the spleen of exposed fish, for all contaminants tested (Figs. 7B and C). This condition is recognized by the presence of large areas of deposition of hemosiderin granules, stained yellowish brown by HE. Control fish did not exhibit any of these areas of deposition. Occasionally, small points of hemosiderin granule accumulation were observed in the spleen of control fish. DHAA exposures beyond 30 days revealed regression of this hemosiderosis condition for 90 and 180 days exposure, since large areas of 

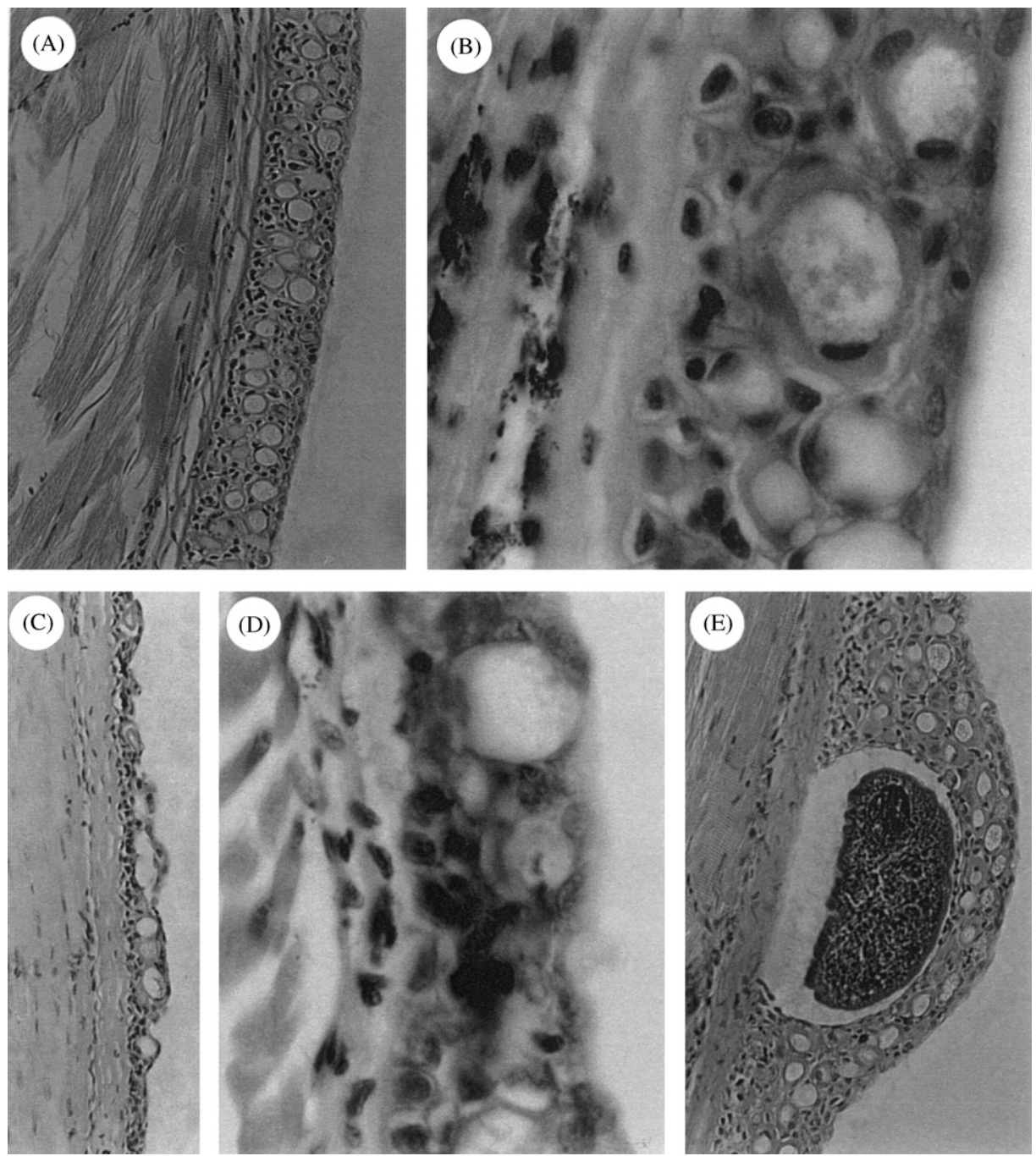

Fig. 4. Photomicrographs of $A$. anguilla L. skin tissue. (A, B) Without pathological alterations. (C, D) Reduction of skin thickness and exfoliated epidermis after exposure to $0.3 \mu \mathrm{M}$ DHAA (30 days). (E) Parasitic infestation (Ichthyophthirius multifiliis) and associated epidermal hyperplasia. Original magnification: $(A, C, E) 260 \times$; (B, D) $1300 \times$. HE stain.

hemosiderin granule accumulation were no longer observed.

\subsubsection{Liver}

Control fish liver generally exhibited a normal mural architecture with hepatocytes presenting a homogeneous cytoplasm and a large spherical nucleus containing one nucleolus (Figs. 8A and B). Histopathological features of the liver varied between fish groups differently exposed.

3.4.5.1. BaP. The most pronounced anomaly detected was the regular appearance of large pigmented macrophage aggregates (PMAs) (Figs. 8C and D), reaching an area of about $25 \mu \mathrm{m}^{2}$. Focal accumulations of inflammatory cells were repeatedly found surrounding PMAs, as well as in other sites eventually related to necrotic hepatocytes. Necrotic cells appeared sporadically (not in clusters). Additionally, there was an accumulation of bile within the hepatocytes - cholestasis - recognized by the appearance of intracytoplasmatic brownish-green pigments.

3.4.5.2. DHAA. Hepatocyte cytoplasmic vacuolization was the most obvious pathological alteration observed. Moreover, this evidence of cell injury was found after all exposure lengths and seems to exhibit a time-related intensity. Associated with this pathological change, accentuated necrosis of single hepatocytes was observed, occasionally with karyolysis. In the most severe situations necrotic cells undergo cytolysis (Figs. 9A and B). PMAs were not found in 30-day DHAA-treated fish. However, for longer exposures, a time-dependent occurrence of PMAs was observed, since a few aggregates were found at 90 days and a considerable number at 180 days of DHAA exposure (Fig. 9D). PMAs were not found in control groups, with the 

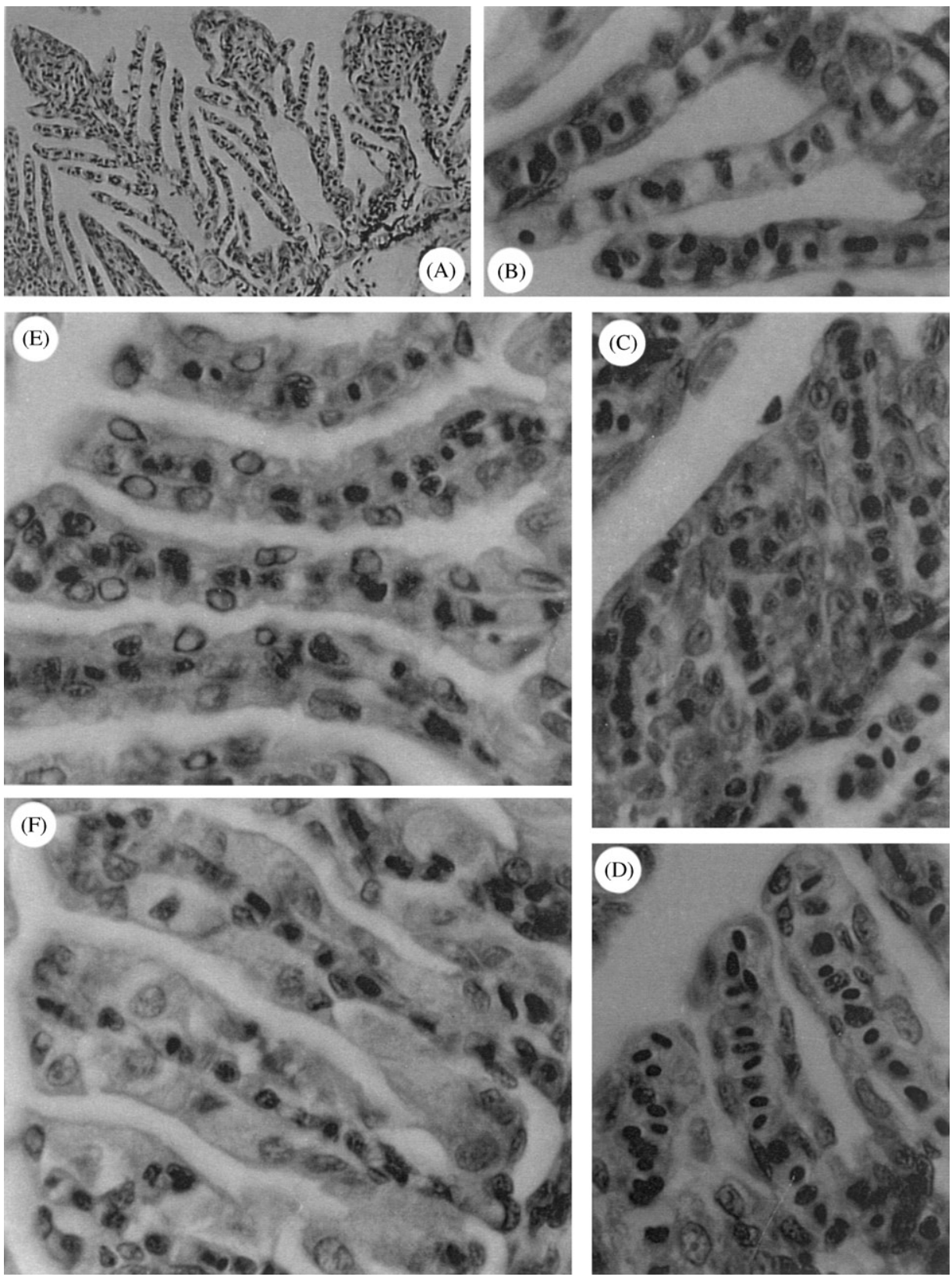

Fig. 5. Photomicrographs of $A$. anguilla L. gill tissue. (A, B) Without pathological alterations. (C) Proliferation of the interlamellar cells after exposure to $12.5 \%$ BKPME (30 days). (D-F), Edematous hypertrophy of covering epithelial cells in the secondary lamellae after 90 (D) and 180 (E, F) days of exposure to $0.3 \mu \mathrm{M}$ DHAA. Original magnification: (A) $205 \times$; (B-E) $1015 \times$. HE stain.

exception of one 90-day control fish, which exhibited a few small groups of pigmented macrophages. Foci of inflammation were observed occasionally in 30- and 90-day-exposed fish, and regularly in 180-day DHAAexposed fish (Figs. 9C and D). After 30 days exposure, atrophic liver was occasionally found where the hepatocytes displayed a cellular size below the normal range (Figs. 9E and F).

3.4.5.3. BKPME. Fish exposed for 30 days to this effluent exhibited a clear altered liver architecture (Fig. 10). Accentuated necrosis and pyknotic nuclei were observed. A loss of parenchymal cells and several isolated hepatocytes could be observed, causing disintegration of the hepatic structure and a decrease in the hepatic parenchyma density. Accentuated frequency of PMAs, as well as inflammatory cell infiltrates, was also detected.

\section{Discussion}

Contaminant effects can weaken fish, rendering them more susceptible to mortality from other causes 

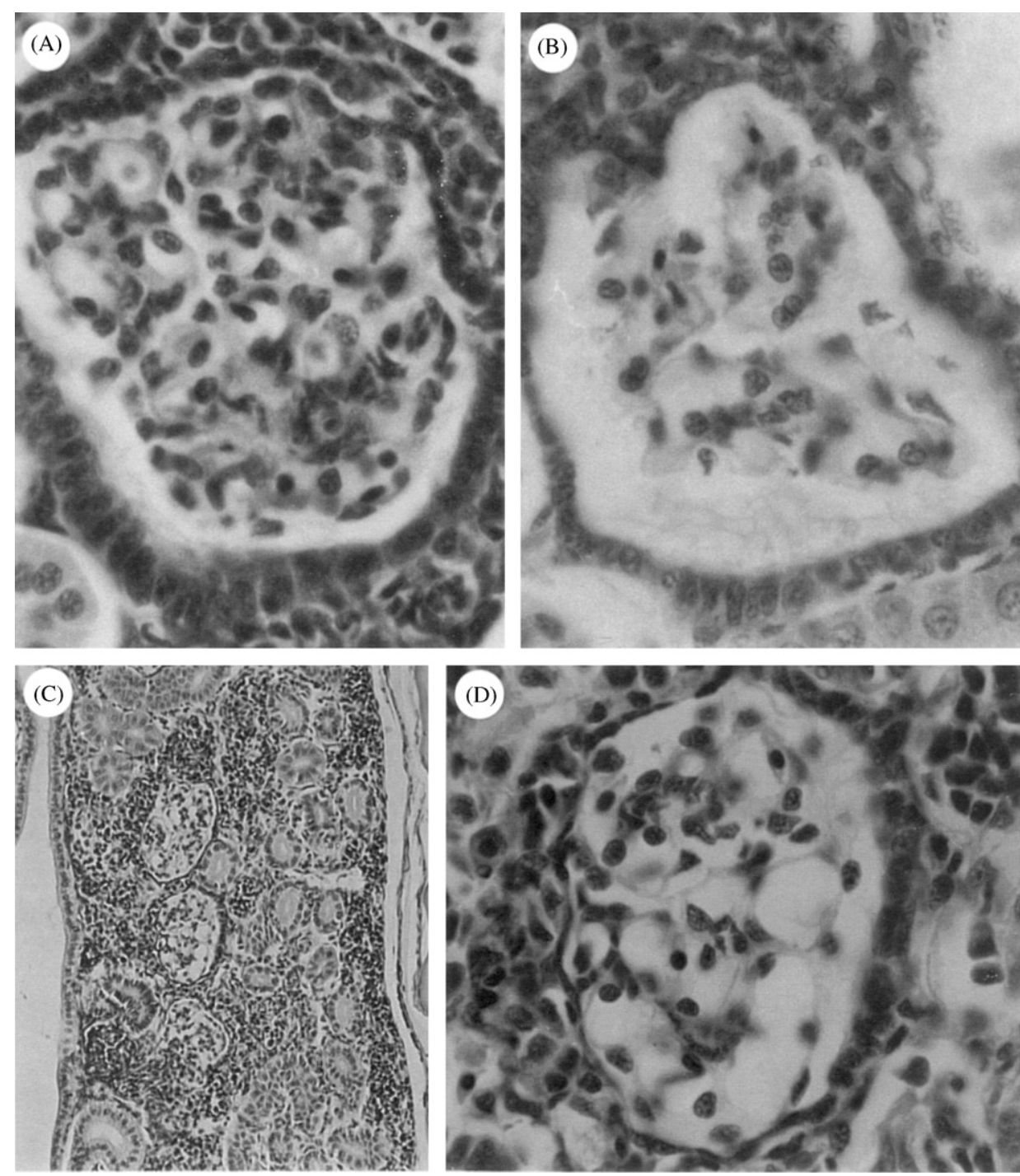

Fig. 6. Photomicrographs of $A$. anguilla L. renal tissue. (A) Renal corpuscle without pathological alterations. (B) Glomerulus destruction after exposure to $0.3 \mu \mathrm{M}$ DHAA (180 days). (C, D) Dilation of blood capillaries on the glomeruli after exposure to $12.5 \%$ BKPME (30 days). Original magnification: $(A, B, D) 1015 \times$; (C) $200 \times$. HE stain.

(Schwaiger et al., 1997). Fish mortality occurring after 30 days exposure to either BaP or BKPME may be regarded as a consequence of both direct toxicant effects of contaminated water (and solid substratum) and secondary effects caused by diseases and parasitism. Therefore, lower concentration ranges are recommended in future long-term experiments.

\subsection{EROD response}

Several fish studies have reported BaP (Wolkers et al., 1996; Pacheco and Santos, 1997), DHAA and BKPME (Martel et al., 1994; Pacheco and Santos, 1999) as EROD inducers. Considering these previous investigations, the $A$. anguilla biotransformation response observed in the current research work seems unexpected, since neither BaP nor BKPME exhibited considerable total EROD induction. The response to shorter DHAA exposures also did not corroborate our previous results, despite the unequivocal total EROD induction exhibited by 180-day DHAA-exposed fish. Hence, the discrepancy between current and previous results may be explained either by differences between fish lots or by a relative lack of sensitivity of EROD methodology concerning the measurement on the whole body.

\subsection{ENA response}

The $A$. anguilla genotoxic response to the contaminants tested confirmed previous investigations where BaP (Hawkins et al., 1990; Pacheco and Santos, 1997), DHAA (Pacheco and Santos, 1999), and BKPME (Das and Nanda, 1986; Al-Sabti and Härdig, 1990; Pacheco and Santos, 1999) were identified as strong fish 

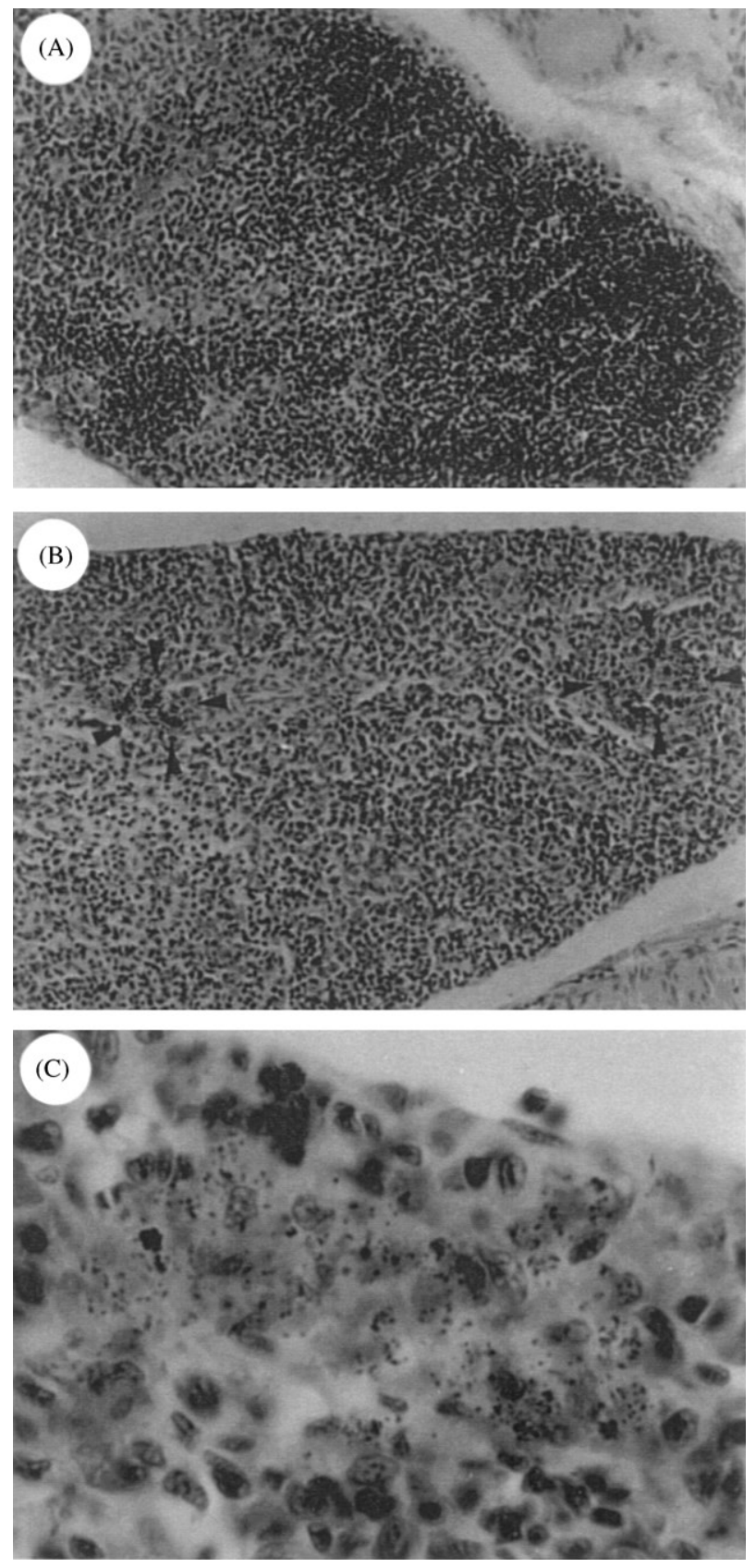

Fig. 7. Photomicrographs of $A$. anguilla L. spleen tissue. (A) Without alterations. (B) Deposition areas of hemosiderin granules. (C) Area delineated by arrowheads in (B). Original magnification: (A, B) $245 \times$; (C) $1230 \times$. HE stain.

mutagens. However, the BaP results reveal a clear doserelated disruption of ENA expression demonstrated by the inability of the highest concentration to induce a significant ENA increase as well as by the inverse doseresponse relationship observed at 30 days exposure. Additionally, the ENA response to $\mathrm{BaP}$ as a function of time demonstrates that only the lowest concentration induces a time-related ENA increase. In terms of DHAA results, it is important to emphasize that, for exposures longer than 30 days, the highest ENA levels were observed for the intermediate concentration. The previous response profile, already found in our recent study with adult eels (Pacheco and Santos, 1999), may also reveal a disturbance of the genotoxicity expression. Relative to BKPME results, the previously reported disturbance was demonstrated by the regular occurrence of an inverse dose-response relationship as well as by the appearance, after 30 days exposure, of ENA levels in treated fish below the control value. Similarly, Das and Nanda (1986) reported an unclear dose dependency for BKPME induction of micronuclei.

The ENA assay evaluation as a biomarker for aquatic contamination suggests that a complete understanding of the hematological dynamics must follow its application and data interpretation.

\subsection{Hematological dynamics (IE frequency)}

Global analysis of these data revealed that IEs were less prevalent in treated fish, suggesting altered hematological dynamics. McLeay (1973) found an increased number of circulating IEs in kraft pulp mill effluentexposed fish. However, our results suggest alterations in the opposite direction, not confirming McLeay findings. On the other hand, in a previous field study (Smith, 1990) a depressed IE frequency was detected in fish inhabiting a PAH-contaminated lake. Furthermore, this effect was correlated to the inability of the fish to develop erythrocytic micronuclei.

Determination of the IE frequency provides important information about hematological dynamics. However, the isolated analysis of this parameter does not allow clear identification of the cause, since it reflects the balance between a variety of factors such as erythropoiesis rate, cell maturation, and intensity of mature cell removal by the spleen.

\subsection{Histological examination}

It was previously suggested (Moore and Myers, 1994) that the use of small fish in histopathological studies represents an advantage, since multiple organs can be easily processed, embedded, and examined. Additionally, small fish are easier to handle and maintain, requiring smaller volumes of contaminated water. From this perspective, the use of big fish in early life stages, adopted in the present study, may provide the same advantages.

The epidermis exfoliation observed in 30-day DHAAtreated fish was probably due to the abrasive effect of the resin acid. In the light of previous studies (Bushnell et al., 1985; Toivola and Isomaa, 1991), an eventual detergent-like action and consequent cell breakdown directly affecting the eel's body surface should also be considered. Resin acids are important components of pulp mill effluents; therefore, DHAA may also be 

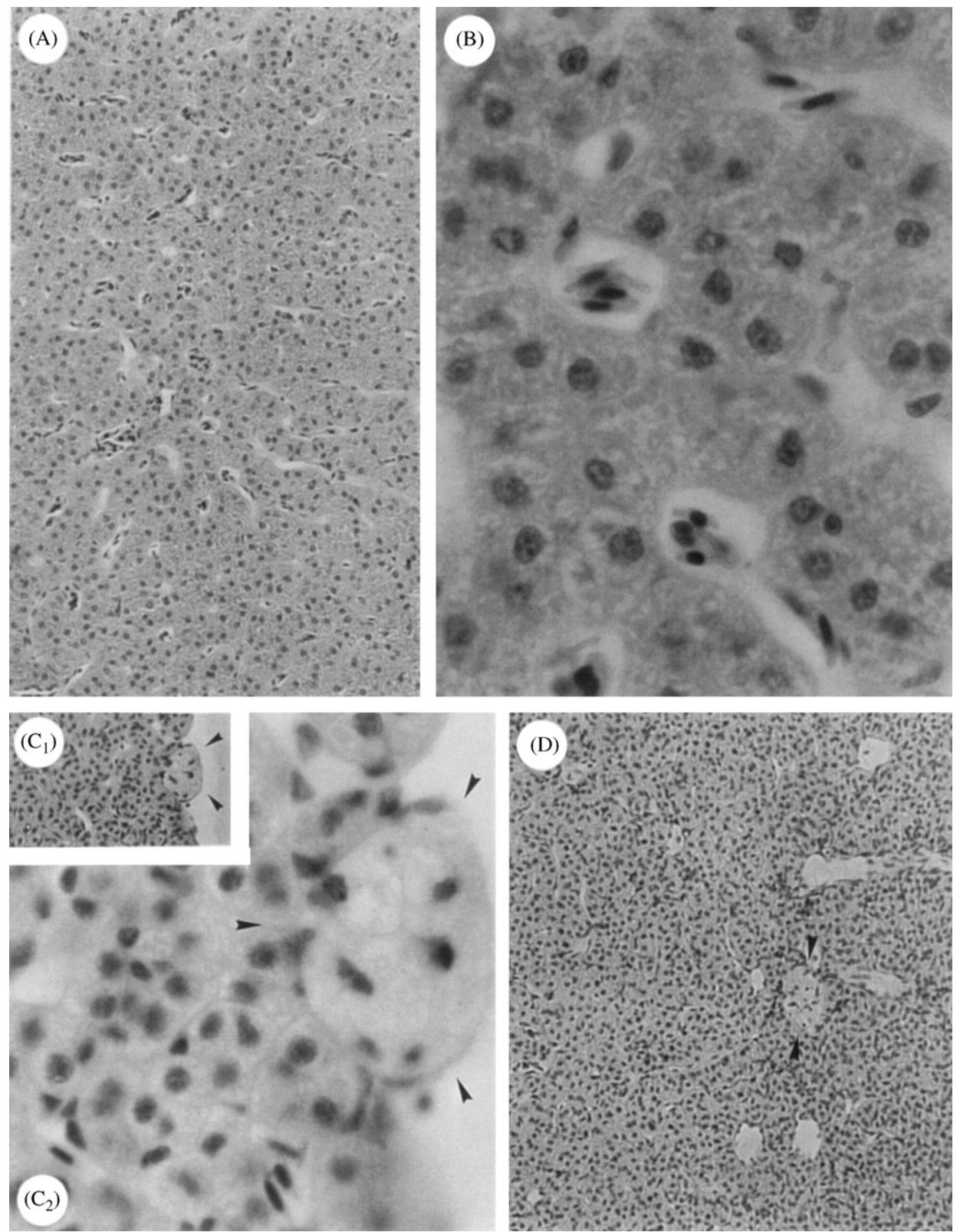

Fig. 8. Photomicrographs of $A$. anguilla L. liver tissue. (A, B) Without pathological alterations; normal architecture. (C, D) Pigmented macrophage aggregates (arrowheads) after exposure to $0.9 \mu \mathrm{M}$ BaP (30 days). Original magnification: $\left(\mathrm{A}, \mathrm{C}_{1}, \mathrm{D}\right) 200 \times ;\left(\mathrm{B}, \mathrm{C}_{2}\right) 1015 \times$. HE stain.

partially responsible for the same histological alteration observed in BKPME-treated fish. With respect to skin lesions, our findings are in agreement with previous BKPME studies that reported skin disruption in adult eel (Santos et al., 1990) and decreased thickness of skin epithelium in coho salmon (Howard et al., 1971; McLeay, 1973). Unexpectedly, our histological examination revealed that eels exposed to DHAA for 90 and 180 days exhibit signs of recovery since a normal skin structure was observed. Howard et al. (1971) also reported a favorable fish adaptation capacity in their study with pulp mill effluents. The lack of parasites or parasitic lesions in the skin of DHAA-treated animals indicates that the above reported abrasive action of DHAA may also be adverse to parasite fixation, preventing this kind of infestation. These results may agree with previous findings, where pulp mill effluents occasionally reduced parasitic infestation (Borton and Hall, 1984).

The structural changes observed in the gills of experimental fish are similar to those previously found after exposure to either DHAA (Tuurala and Soivio, 1982) or pulp mill effluents (Santos et al., 1990). These histopathological alterations may have important 

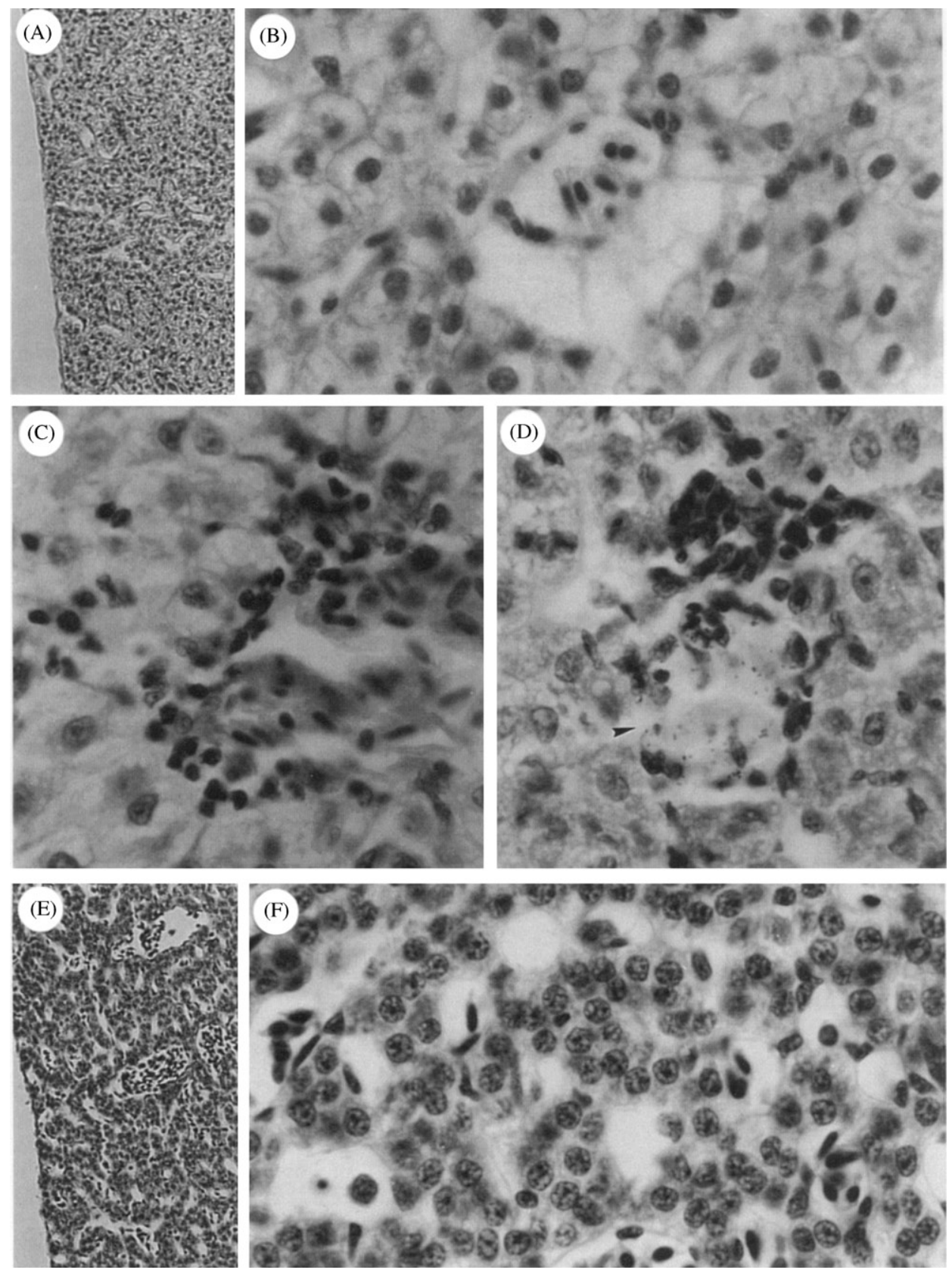

Fig. 9. Photomicrographs of A. anguilla L. liver tissue after exposure to $0.3 \mu \mathrm{M}$ DHAA. (A, B) Cytoplasmic vacuolization, necrosis, karyolysis, and cytolysis (30 days). (C) Focuses of phagocytic cells (C) sometimes associated with (D) pigmented macrophage aggregates (180 days). (E, F) Hepatocyte atrophy (30 days). Original magnification: (A, E) $205 \times$; (B-F) $1015 \times$. HE stain.

adverse consequences on fish health, particularly due to the obstruction of oxygen diffusion across the gills and the impairment of osmoregulatory function.

The splenic hemosiderosis observed in all 30-dayexposed groups indicates increased erythrocytic catabolism. A similar effect was previously noted in fish exposed to BKPME (Santos et al., 1990; Couillard and Hodson, 1996). According to Couillard and Hodson (1996), the presence in these effluents of resin acids or other hemolytic compounds may accelerate the rate of erythrocyte destruction, leading to the observed splenic hemosiderosis. The increment in hemolysis may result in a decrease in the number of mature erythrocytes in the circulating blood (Hibiya, 1982). Confirmation of occurrence of hemolytic anemia was not possible in the present study, since the volume of blood we were able to collect was not sufficient to count the erythrocytes cubic millimeter of blood. DHAA exposure for 90 and 180 days revealed regression of the hemosiderosis, indicating erythrocytic catabolism levels close to the 

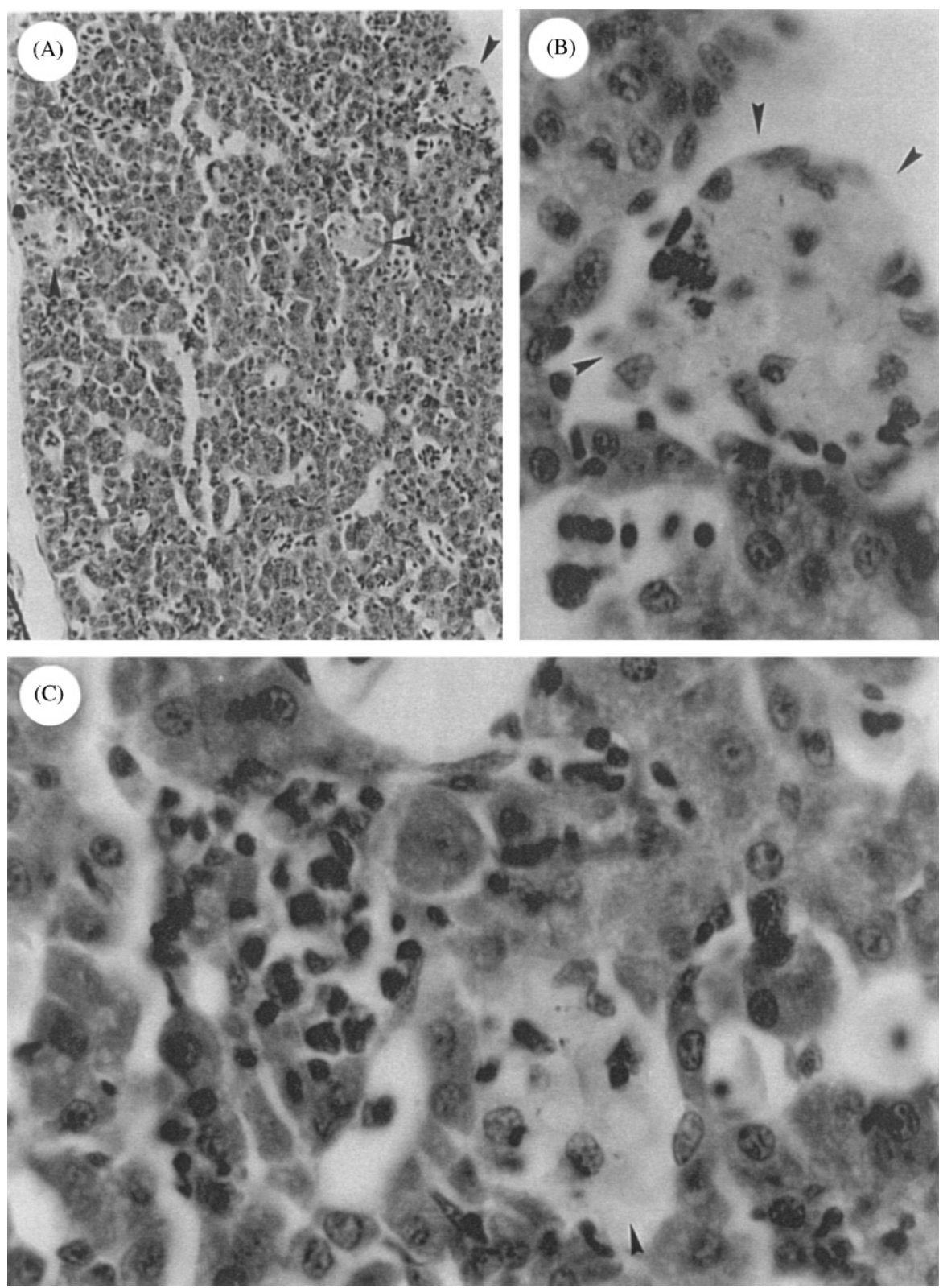

Fig. 10. Photomicrographs of A. anguilla L. liver tissue revealing altered architecture, decreased parenchyma density, isolated hepatocytes, necrosis, pyknosis, inflammatory cells and pigmented macrophage aggregates (arrowheads) after exposure to 12.5\% BKPME (30 days). Original magnification: (A) $245 \times$; (B, C) $1230 \times$. HE stain.

control level. As previously reported for skin disruption, this fact may be interpreted as a tendency for splenic recovery. An alternative hypothesis should be presented, concerning the development of a degenerative process that induces a decrease in the spleen's capacity to remove aged and abnormal erythrocytes, due to progressive exhaustion of the metabolic steps involved in that function. However, the significant ENA increase and iron removal from the spleen do not provide strong support for the last suggestion.

The renal glomerular injury that was observed in the present 30-day BKPME and 180-day DHAA exposures might impair glomerular filtration. Histological alterations in the renal tubules of BKPME-exposed eels have previously been detected (Santos et al., 1990).

The increased density of hepatic PMAs generally found in treated fish reflects important liver lesions. PMAs are focal accumulations of pigmented macrophages, which may contain four types of brown pigments: melanin, lipofuscin, ceroid, and hemosiderin. According to Myers et al. (1987), this alteration is often associated with a degenerative-necrotic condition. More recently, Couillard and Hodson (1996) studied the proliferation of PMAs in BKPME-exposed fish and 


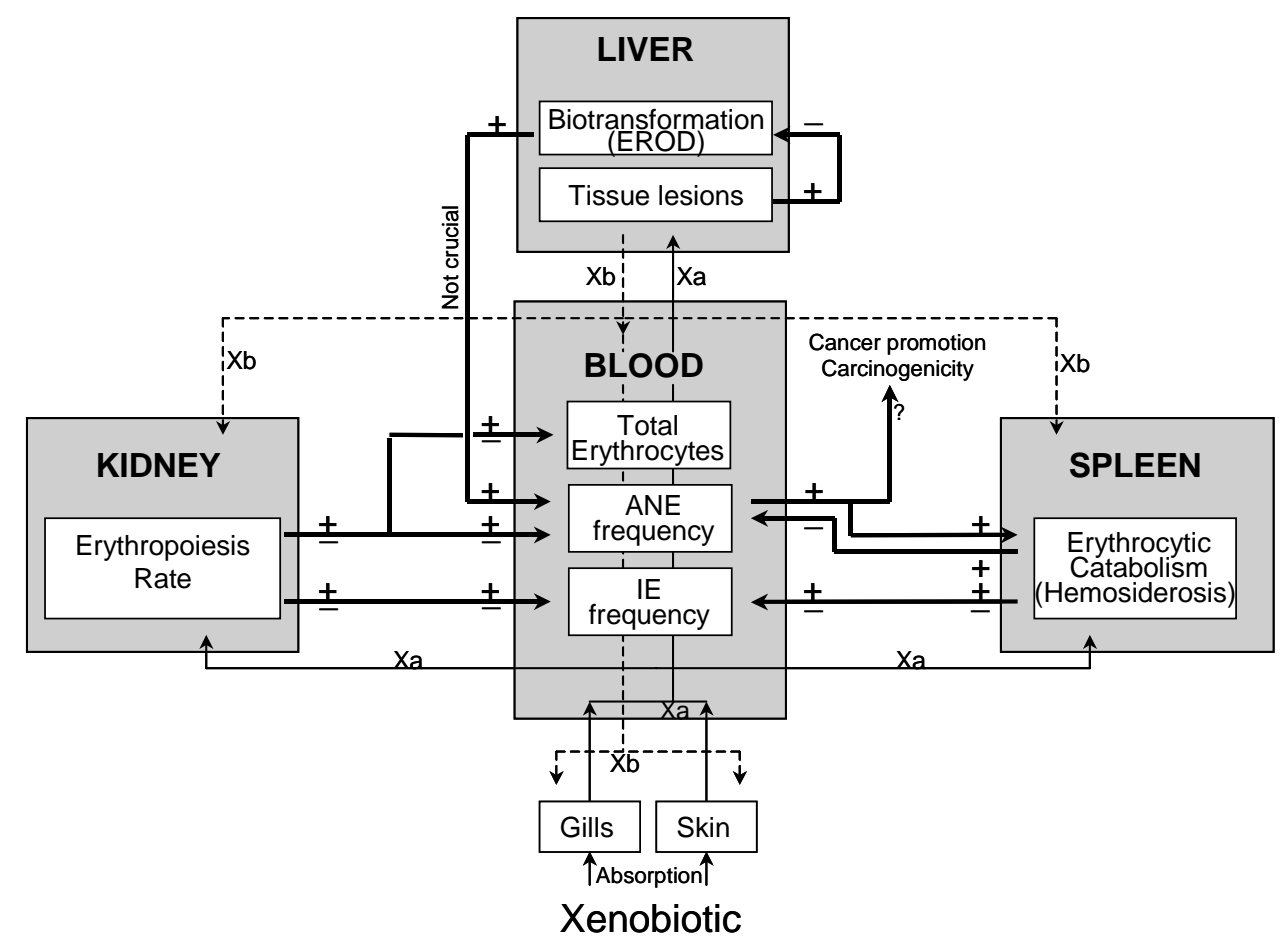

Fig. 11. Schematic representation of the interactions between the different levels of biological response. Xa, absorbed xenobiotic (or parental compound); $\mathrm{Xb}$, biotransformed xenobiotic (or subsequent metabolite).

suggested that several known toxic effects of these effluents could contribute to this response, including CYP1A induction, toxic hemolysis, and impaired macrophage function. These statements are also applicable to splenic hemosiderosis. The same authors suggested PMA density as a useful marker of BKPME toxicity. In experimental groups where the highest PMA densities were found a considerable portion of the hepatic parenchyma was occupied by these aggregates. Consequently, the liver's biotransformation capacity may have been substantially reduced. That reduction is probably involved in the decreased resistance to contaminants and survival levels displayed in the current study.

The cholestasis recognizable in the liver of $\mathrm{BaP}$ treated fish is a manifestation of a pathophysiological condition, attributable to a failure of the metabolism or excretion of bile pigments. Excretion of bilirubin depends on its water solubility obtained through conjugation with glucuronic acid. This conjugation is catalyzed by the enzyme UDP-glucuronyl transferase. A decreased capacity to glucuronidate bilirubin may be the primary reason for this liver dysfunction (Nikinmaa and Oikari, 1982). This decrease may be related either to a conjugation enzyme inhibition or to exhaustion of the conjugation process, particularly in terms of activated glucuronic acid.

The separation between adjacent hepatocytes observed in the livers of BKPME-treated fish, probably related to cell necrosis, indicates degeneration of structural proteins in the hepatocyte membrane, which commonly maintain the hepatic parenchyma as a compact homogeneous tissue. The time-related liver vacuolization detected in DHAA-exposed fish signals an intracellular degenerative process suggestive of underlying metabolic disorders. This anomaly was previously noted in resin acid-treated fish (Mattsoff and Oikari, 1987) and BKPME-treated fish (Axelsson and Norrgren, 1991). The hepatocyte pyknosis and necrosis detected in our liver examination may be regarded as nonspecific lesions since they were generally found in all treated groups. Several investigators previously related this cellular deterioration to BKPME exposure (Santos et al., 1990; Axelsson and Norrgren, 1991).

The previously demonstrated carcinogenicity (hepatic and non-hepatic) of $\mathrm{BaP}$ (Hendricks et al., 1985; Hawkins et al., 1990) and BKPME (Smith and Rokosh, 1989; Kinae et al., 1990) could not be confirmed by our data, probably due to the short exposures. With respect to DHAA, prolonged exposure up to 180 days did not induce neoplastic lesions, suggesting the absence of carcinogenic potential or a need for longer exposures.

\subsection{Interaction of biomarkers}

The interdependency of the different biomarkers suggested by our results is summarized in Fig. 11. 
Considering that, in the vast majority of points in time, ENA induction was not associated with a preceding or simultaneous EROD induction, we suggest that this genotoxic response does not depend on a very high biotransformation activity. However, the highest ENA levels were observed when fish also exhibit the highest EROD activity levels, suggesting that, particularly for DHAA, a strong biotransformation activity may potentiate the expression of genotoxicity. Our results also indicate that the eventual interdependence between the previous responses may vary with the contaminant.

Concerning the 30-day exposure, parallel analysis of ENA and spleen histological data demonstrates that the disturbances observed in ENA expression coincide with an accentuated hemosiderosis. Therefore, the hypothesis that ENA expression was disturbed by increased erythrocytic catabolism seems to be confirmed. We suggest that the increment in cell removal may be a splenic response to the increased frequency of circulating abnormal erythrocytes. This idea is based on the assumption that nuclear abnormalities induce functional disorders with a consequent expression on the cell membrane, allowing their identification by the spleen and consequent catabolism. Previously, other authors (Das and Nanda, 1986; Brunetti et al., 1988) suggested a dose-related cytotoxicity, which killed the erythrocytes instead of forming a nonlethal nuclear lesion, explain the impairment in expression of nuclear abnormalities. Therefore, to explain the simultaneous occurrence of splenic hemosiderosis and disturbances in ENA expression, the conjugation of both mechanisms should also be accepted, namely, in the presence of xenobiotics with hemolytic and genotoxic properties.

Our IE results for the 30-day exposures to the highest concentrations do not refute the hypothesis that ENA expression was also conditioned by a reduced erythropoiesis rate. This effect may result either from inhibition of DNA synthesis (Williams and Metcalfe, 1992) or from direct inhibition of erythropoiesis (Dinnen et al., 1988). With respect to the unchanged erythropoiesis rate, the increased removal of mature erythrocytes should lead to an increase in IE frequency. However, our IE results revealed the opposite tendency, indicating, therefore, the probable occurrence of simultaneous erythropoiesis inhibition. With respect to longer DHAA exposures, ENAs seem to be more easily expressed concomitantly with regression of splenic hemosiderosis. Considering this regression and the observed IE decrease, inhibition of erythropoiesis seems to be evident as a result of the prolonged DHAA exposure. This inhibition was not enough to prevent ENA expression but may justify the low ENA levels observed at the highest DHAA concentration.

Our data suggest that genotoxic manifestations are not necessarily followed by induction of neoplasms.
Similarly, Metcalfe et al. (1995) detected BKPME mutagenic activity without consequent carcinogenicity. However, these authors suggested that the effluent might have neoplasm-promoting activity.

\section{Conclusions}

Our results support the importance of prolonged fish studies in the evaluation of toxicity of environmental contaminants. The capacity of all contaminants tested to induce several organ and tissue lesions as well as genotoxic effects was demonstrated. Additionally, it can be stated that:

i. A. anguilla (glass eel) seems to be a good organism to carry out long-term studies.

ii. ENA assay was confirmed as an effective and suitable genotoxic biomarker also applicable to long-term exposures. However, its use may be inadequate for situations of intense contamination since some disturbances of genotoxicity expression may occur. These disturbances were confirmed to depend on the balance between increased splenic erythrocytic catabolism and erythropoiesis rate reduction. Furthermore, that balance may vary with the contaminant, concentration, and exposure length.

iii. Our histopathological findings showed the usefulness of nonneoplastic lesions as indicators of fish exposure to pollutants.

iv. The combination of biochemical, genetic, and histological biomarkers provides useful and sensitive tools in the investigation of sublethal effects induced by environmental contaminants. Furthermore, this strategy contributes to the establishment of a causal relationship between contaminant exposure and various biological responses.

\section{Acknowledgments}

This research was supported by the program PRAXIS XXI (Contract PCNA/C/BIA/175-96) and by the Aveiro University Research Institute/CZCM.

\section{References}

Addison, R.F., Willis, D.E., Zinck, M.E., 1994. Liver microsomal mono-oxygenase induction in winter flounder (Pseudopleuronectes americanus) from a gradient of sediment PAH concentrations at Sydney Harbour, Nova Scotia. Mar. Environ. Res. 37, 283-296.

Al-Sabti, K., Härdig, J., 1990. Micronucleus test in fish for monitoring the genotoxic effects of industrial waste products in the Baltic Sea, Sweden. Comp. Biochem. Physiol. C 97, 179-182. 
Axelsson, B., Norrgren, L., 1991. Parasite frequency and liver anomalies in tree-spined stickleback, Gasterosteus aculeatus (L.), after long-term exposure to pulp mill effluents in marine mesocosms. Arch. Environ. Contam. Toxicol. 21, 505-513.

Bailey, N.T., 1959. Statistical Methods in Biology. English University Press, London.

Borton, D.L., Hall, T.J., 1984. Observations of the conditions of organs and tissues of fish exposed to biologically treated kraft mill effluent. Technical Bulletin No. 419, National Council of the Paper Industry for Air and Stream Improvement, New York, 124pp.

Brunetti, R., Majone, F., Gola, I., Beltrame, C., 1988. The micronucleus test: examples of application to marine ecology. Mar. Ecol. Prog. Ser. 44, 65-68.

Burke, M.D., Mayer, R.T., 1974. Ethoxyresorufin: direct fluorometric assay of a microsomal- $O$-deethylation which is preferentially inducible by 3-methylcholanthrene. Drug. Metab. Dispos. 2, 583-588

Bushnell, P.G., Nikinma, M., Oikari, A., 1985. Metabolic effects of dehydroabietic acid on rainbow trout erythrocytes. Comp. Biochem. Physiol. C 81, 391-394.

Couillard, C.M., Hodson, P.V., 1996. Pigmented macrophage aggregates: a toxic response in fish exposed to bleached-kraft mill effluent? Environ. Toxicol. Chem. 15, 1844-1854.

Das, R.K., Nanda, N.K., 1986. Induction of micronuclei in peripheral erythrocytes of the fish, Heteropneustes fossilis, by mitomycin $\mathrm{C}$ and paper mill effluent. Mutat. Res. 175, 67-71.

Di Guilio, R.T., Washburn, P.C., Wenning, R.J., Winston, G.W., Jewell, C.S., 1989. Biochemical responses in aquatic animals: a review of determinants of oxidative stress. Environ. Toxicol. Chem. 8, 1103-1123.

Dinnen, R.D., Tomlinson, S.M., Hart, D., Chopra, C., Heddle, J.A., 1988. Application of a micronucleus assay to the peripheral blood cells of rainbow trout, Salmo gairdneri. Can. Tech. Rep. Fish. Aquat. Sci. 1607, 69-78.

Everaarts, J.M., 1995. Dna integrity as a biomarker of marine pollution: strand breaks in seastar (Asterias rubens) and dab (Limanda limanda). Mar. Pollut. Bull. 31, 431-438.

Gornall, A.C., Bardawill, C.J., David, M.M., 1949. Determination of serum proteins by means of the biuret reaction. J. Biol. Chem. 177, 751-766.

Harvey, J.S., Lyons, B.P., Waldock, M., Parry, J.M., 1997. The application of the ${ }^{32} \mathrm{P}$-postlabelling assay to aquatic biomonitoring. Mutat. Res. 38, 77-88.

Hawkins, W.E., Walker, W.W., Overstreet, R.M., Lytle, J.S., Lytle, T.F., 1990. Carcinogenic effects of some polycyclic aromatic hydrocarbons on the Japanese medaka and guppy in waterborne exposures. Sci. Total Environ. 94, 155-167.

Hendricks, J.D., Meyers, T.R., Shelton, D.W., Casteel, J.L., Bailey, G.S., 1985. Hepatocarcinogenicity of benzo[a]pyrene to rainbow trout by dietary exposure and intraperitoneal injection. J. Natl. Cancer Inst. 74, 839-850.

Hibiya, T., 1982. An Atlas of Fish Histology-Normal and Pathological Features. Kodansha, Tokyo.

Howard, T.E., McLeay, D.J.,Walden, C.C., 1971. Sub-lethal effects of bleached kraft mill effluents to fish. CPAR Project Report 9-2, Pulp and Paper Pollution Abatement, Ottawa, Canada, 63pp.

Jaylet, A., Deparis, P., Ferrier, V., Grinfeld, S., Siboulet, R., 1986. A new micronucleus test using peripheral blood erythrocytes of the newt Pleurodeles waltl to detect mutagens in fresh-water pollution. Mutat. Res. 164, 245-257.

Kinae, N., Yamashita, M., Tomita, I., Kimura, I., Ishida, H., Kumai, H., Nakamura, G., 1990. A possible correlation between environmental chemicals and pigment cell neoplasia in fish. Sci. Total Environ. 94, 143-153.

Lange, U., Danischewski, D., Siebers, D., 1993. Regional variability and sexual differences in ethoxyresorufin $O$-deethylase activities and cytochrome P450 concentrations in the liver of mature dab (Limanda limanda L.) in the German Bight. In: Braumbeck, T., Hunke, W., Segner, H. (Eds.), Fish Ecotoxicology and Ecophysiology. VCH Verlag Chemie, Weinheim.

Martel, P.H., Kovacs, T.G., O’Connor, B.I., Voss, R.H., 1994. A survey of pulp and paper mill effluents for their potential to induce mixed function oxidase enzyme activity in fish. Water Res. 28, $1835-1844$.

Mattsoff, L., Oikari, A., 1987. Acute hyperbilirubinaemia in rainbow trout (Salmo gairdneri) caused by resin acid. Comp. Biochem. Physiol. C 88, 263-268.

McLeay, D.J., 1973. Effects of a 12-hr and 25-day exposure to kraft pulp mill effluent on the blood and tissues of juvenile coho salmon (Oncorhynchus kisutch). J. Fish. Res. Board Can. 30, 395-400.

Metcalfe, C.D., Nanni, M.E., Scully, N.M., 1995. Carcinogenicity and mutagenicity testing of extracts from bleached kraft mill effluent. Chemosphere 30, 1085-1095.

Monod, G., Vindimian, E., 1991. Effect of storage conditions and subcellular fractionation of fish and cytochrome $P$-450-dependent enzymatic activities used for the monitoring of water pollution. Water Res. 25, 173-177.

Moore, M.J., Myers, M.S., 1994. Pathobiology of chemical-associated neoplasia in fish. In: Malins, D.C., Ostrander, G.K. (Eds.), Aquatic Toxicology: Molecular, Biochemical, and Cellular Perspectives. CRC Press, Lewis Publishers, Boca Raton, FL, pp. 327-386.

Moore, M.N., Simpson, M.G., 1992. Molecular and cellular pathology in environment impact assessment. Aquat. Toxicol. 22, 313.

Myers, M.S., Rhodes, L.D., McCain, B.B., 1987. Pathologic anatomy and patterns of occurrence of hepatic neoplasms, putative preneoplastic lesions, and other idiopathic hepatic conditions in English sole (Parophrys vetulus) from Puget Sound, Washington. J. Natl. Cancer Inst. 78 (2), 333-363.

Nikinmaa, M., Oikari, A., 1982. Physiological changes in trout (Salmo gairdneri) during a short-term exposure to resin acids and during recovery. Toxicol. Lett. 14, 103-110.

Pacheco, M., Santos, M.A., 1996. Induction of micronuclei and nuclear abnormalities in the erythrocytes of Anguilla anguilla L. exposed either to cyclophosphamide or to bleached kraft pulp mill effluent. Fresenius Environ. Bull. 5, 746-751.

Pacheco, M., Santos, M.A., 1997. Induction of erod activity and genotoxic effects by polycyclic aromatic hydrocarbons and resin acids on the juvenile eel (Anguilla anguilla L.). Ecotoxicol. Environ. Saf. 38, 252-259.

Pacheco, M., Santos, M.A., 1998. Anguilla anguilla L. liver EROD and erythrocytic nuclear abnormalities induction by cyclophosphamide and PAHs. Ecotoxicol. Environ. Saf. 40, 71-76.

Pacheco, M., Santos, M.A., 1999. Biochemical and genetic responses of adult eel (Anguilla anguilla L.) to resin acids and pulp mill effluent: laboratory and field experiments. Ecotoxicol. Environ. Saf. 42, 81-93.

Santos, M.A., Pires, F., Hall, A., 1990. Metabolic effects of kraft mill effluents on the eel Anguilla anguilla L. Ecotoxicol. Environ. Saf. $20,10-19$.

Schwaiger, J., Fent, K., Stecher, H., Ferling, H., Negele, R.-D., 1996. Effects of sublethal concentrations of triphenyltriacetate on rainbow trout (Oncorhynchus mykiss). Arch. Environ. Contam. Toxicol. 30, 327-334.

Schwaiger, J., Wanke, R., Adam, S., Pawert, M., Honnen, W., Triebskorn, R., 1997. The use of histopathological indicators to evaluate contaminant-related stress in fish. J. Aquat. Ecosystem Stress Recovery 6, 75-86.

Smith, I.R., 1990. Erythrocytic micronuclei in wild fish from Lakes Superior and Ontario that have pollution-associated neoplasia. J. Great Lakes Res. 16 (1), 139-142. 
Smith, I., Rokosh, D.A., 1989. An epidemiological study of a white sucker (Catostomus commersoni) population inhabiting the Kaministiquia River, Thunder Bay, Ontario. Proceedings of the 10th Annual Meeting of Society of Environmental Toxicology Chemistry, Toronto, Ont., Canada, October 28-November 2, 1989, p. 262.

Teh, S.J., Adams, S.M., Hinton, D.E., 1997. Histopathologic biomarkers in feral freshwater fish populations exposed to different types of contaminants stress. Aquat. Toxicol. 37, 51-70.

Toivola, D.M., Isomaa, B., 1991. Effects of dehydroabietic acid on the erythrocyte membrane. Chem.-Biol. Interact. 79, 65-78.
Tuurala, H., Soivio, A., 1982. Structural and circulatory changes in the secondary lamellae of Salmo gairdneri gills after sublethal exposure to dehydroabietic acid and zinc. Aquat. Toxicol. 2, 21-29.

Williams, R.C., Metcalfe, C.D., 1992. Development of an in vivo hepatic micronucleus assay with rainbow trout. Aquat. Toxicol. 23, 193-202.

Wolkers, J., Jørgensen, E.H., Nijmeijer, S.M., Witkamp, R.F., 1996. Time-dependent induction of two distinct hepatic cytochrome P4501A catalytic activities at low temperatures in Arctic char (Salvelinus alpinus) after oral exposure to benzo[a]pyrene. Aquat. Toxicol. 35, 127-138. 